\title{
Mis derechos y los derechos del otro. Reflexiones fenomenológicas en torno al problema del fundamento de los derechos humanos
}

\section{My Rights and the Rights of the Other. Phenomenological Reflections on the Foundation of Human Rights}

\author{
Luis Niel \\ CONICET / Universidad Nacional del Litoral, Argentina \\ luisniel@yahoo.com \\ Recibido: 28/06/2016 • Aceptado: 5/10/2016
}

\begin{abstract}
Resumen
El artículo tiene como meta presentar una reflexión fenomenológica de los derechos humanos [DDHH]. En una primera parte introductoria ofreceremos una breve caracterización jurídico-conceptual del concepto de «derecho», siguiendo la dogmática de Carlos Nino para mostrar que los DDHH no se pueden justificar desde la ciencia jurídica. En la segunda parte nos detendremos en nuestra presentación positiva, en un intento de aproximación fenomenológica al problema de los DDHH, que se realizará en diferentes niveles de constitución. Así, mostraremos: primero, cómo se puede entender el «ser hombre» del otro, a partir de la diferenciación entre el reconocimiento empático y el moral; segundo, cómo los derechos más fundamentales, a saber, la libertad y el derecho a mi vida, se constituyen en un sentido genético básico a partir de la relación subjetiva-intersubjetiva, y cómo dicha constitución surge en directa correlación con el reconocimiento del otro y de sus derechos, en el sentido experiencial más elemental del término; tercero, cómo, desde una perspectiva fenomenológica transgenética o intergeneracional, se puede describir y así explicar el origen histórico de los DDHH en tanto «proto-fundación (Urstiftung) de sentido», que instituye legitimidad y validez en tanto acontece en la historia. Presentaremos la propuesta fenomenológica como una alternativa a la dicotomía clásica entre iusnaturalismo e iuspositivismo.
\end{abstract}

Palabras clave: derechos humanos, fenomenología, libertad, otro, vida. 


\begin{abstract}
The article's goal is to present a phenomenological reflection on Human Rights [HR]. In a first introductory section we will outline a brief juridicalconceptual characterization of the concept of «right», following Carlos Nino's thought in order to show that HR cannot be justified based on the legal science. In the second part we will present our own account of HR out of a phenomenological perspective, which will be developed in different levels of constitution. Hence, we will show, first, how to rightly understand the «being human» of the other, based on the distinction between the empathic and the moral recognition; second, how the most basic rights, i.e. freedom and the right to live are constituted in a very basic genetic sense, based on the subjective-intersubjective relation, and how this constitution arises in a direct correlation with the recognition of the other and of his/ her own rights, in the most basic experiential meaning of the term; third, how, from a phenomenological transgenetic or intergenerational perspective, it is possible to describe and thus explain the historical origin of HR by means of the concept of «primal-institution -Urstiftung- of sense», that institutes legitimacy and validity as it happens within history. We will present this phenomenological account as an alternative to the classical dichotomy between iusnaturalism and iuspositivism.
\end{abstract}

Keywords: Freedom, Human Rights, Life, Other, Phenomenology. 
Hoy, los derechos humanos (en adelante «DDHH») constituyen uno de los temas y tópicos más recurrentes, debatidos y mencionados en esferas tan diferentes como heterogéneas que van desde el ámbito estrictamente académico hasta las cuestiones jurídico-políticas de orden mundial. Ahora, es innegable, asimismo, que la «cuestión de los DDHH» no siempre viene de la mano de la claridad conceptual que uno esperaría y, en muchos casos, la misma se encuentra entremezclada espuriamente con cuestiones políticas, ideológicas y económicas. Dicho status quo hace más urgente que nunca las siguientes preguntas: ¿Qué son los DDHH? ¿Son derechos naturales, positivos o de otra índole misteriosa? ¿Cuál es su origen histórico? ¿Cuál es su estatuto jurídico-ontológico, si es que, en general, puede decirse que lo tienen? ¿Son instituciones meramente positivas, fruto de acuerdos jurídicos, o son derechos inherentes al hombre, que transcienden los límites de toda facticidad? Y quizás, la pregunta más importante sea: ¿podemos dar un fundamento (filosófico, fenomenológico) a los DDHH, más allá del mero acto positivo del legislador?

Actualmente, la filosofía del derecho, al menos en sus líneas más «populares», parece conducirnos por un derrotero que lleva indefectiblemente a una suerte de «relativismo» ${ }^{1}$ anti- o post-fundacionalista. En este marco, nos encontramos con posiciones muy heterogéneas que van desde un iuspositivismo radical, hasta cierto relativismo propio de las llamadas - de un modo tan apresurado como, irónicamente, acrítico- escuelas «críticas» de base postmoderna, postestructuralista, deconstruccionista, etc. Así, en particular, en el marco de estas posiciones autodenominadas «críticas», una constante parece ser la laxitud filosófica con la que se promueve un ejercicio superador de la «razón occidental», una reducción de la misma a una intertextualidad infinita e indefinida, o bien una proliferación

1 Cuando hablamos aquí de «relativismo» nos referimos exclusivamente a toda posición que niegue la posibilidad de una instancia fundacional. 
vacua - valga la redundancia- de significantes vacíos. Esta explícita negación al problema del fundamento - en general a cualquier instancia de fundamentación-, conlleva por implicación inclusiva una incapacidad de dar cuenta de los DDHH.

De este modo, nos encontramos con un profundo contraste entre el rechazo explícito a todo intento «fundante»y la enorme actualidad político-jurídica de los DDHH. En efecto, es hoy un lugar común la referencia constante a los mismos: abogamos por los DDHH de las minorías étnicas, de las víctimas de genocidios, de los perseguidos políticos; exigimos juicios de lesa humanidad por violaciones de los DDHH; incluso aún, los DDHH se multiplican y se vuelven cada vez más complejos. Hoy se habla incluso de DDHH de «cuarta generación». Pedimos, así, derechos a las diferencias de género, al multiculturalismo, a la libre manifestación de creencias, credos y religiones, al aborto, pero también derechos sociales, como el derecho a la vivienda, a la alimentación, a la seguridad social, a la asistencia médica universal, e incluso al medio ambiente, etc.

No es difícil constatar que, por lo general, en la vida práctica subyace a todas estas manifestaciones la convicción tácita de que estos derechos, más allá de cualquier ordenamiento jurídico positivo, están garantizados por nuestra misma condición de ser hombres, es decir, por la dignidad humana misma, que no puede ser doblegada ni contradicha por ninguna ley positiva. Pero, por otro lado, nos acosan, casi sin darnos cuenta, las sombras de los fantasmas de nuestra época «post-fundacionalista» que mencionamos arriba. Entonces, ¿podemos hablar de los derechos «humanos», del «hombre» o de la «humanidad», y negar al mismo tiempo las ideas «humano», «hombre», «humanidad»? ¿Se puede exigir juicios de lesa humanidad por crímenes políticos y al mismo tiempo adscribir a una posición relativista, que niega la idea de libertad, de responsabilidad, de naturaleza, y de derechos y obligaciones? Las preguntas se podrían multiplicar al infinito. En cualquier caso, uno de los rasgos más notorios de nuestra época parece ser esta patente y flagrante contradicción performativa entre nuestros discursos teóricos y nuestras demandas en la esfera práctica. 
El artículo tiene como meta presentar una reflexión fenomenológica de los DDHH. Es menester aclarar en este contexto que el mismo no pretende ser una exégesis de la fenomenología de Edmund Husserl. En tal sentido, toda apropiación de conceptos de Husserl se realiza con la explícita intención de desarrollar libremente algunas ideas y, por ello, no siempre se respeta el sentido dado por el padre de la fenomenología a dichos conceptos. La intención es meramente reflexionar libre y fenomenológicamente sobre temas que Husserl nunca analizó, como los DDHH, reflexión que dista de agotarse en el presente artículo; de este modo, el presente pretende ser sólo un puntapié inicial en lo que respecta a reflexiones fenomenológicas en torno a las temáticas aquí analizadas.

Primero, ofreceremos una breve caracterización jurídico-conceptual del concepto de «derecho», siguiendo la dogmática de Carlos Nino; la finalidad de dicha incursión será mostrar que los DDHH no se pueden justificar desde la ciencia jurídica. Segundo, presentaremos un intento de aproximación fenomenológica al problema de los DDHH que se realizará en diferentes dimensiones que van de la esfera de constitución genética-intersubjetiva de la propia subjetividad, a la dimensión histórica, trans-generacional. Así, mostraremos: en primer lugar, cómo se puede entender el «ser hombre» del otro, a partir de la diferenciación entre lo empático y lo moral; en segundo lugar, cómo los derechos más fundamentales, a saber, la libertad y la afirmación de mi vida, se constituyen en un sentido genético básico a partir de la relación subjetiva-intersubjetiva, y cómo dicha constitución surge en directa correlación con el reconocimiento del otro y de sus derechos, en el sentido experiencial más elemental del término; en tercer lugar, cómo, desde una perspectiva fenomenológica transgenética o intergeneracional, se puede describir y, así, explicar el origen histórico de los DDHH en tanto «proto-fundación (Urstiftung) de sentido», que instituye legitimidad y validez, sobre la base de la misma facticidad en tanto acontece en la historia. Presentaremos la propuesta fenomenológica como una alternativa a la dicotomía clásica entre iusnaturalismo e iuspositivismo. 
Enfoque jurídico-conceptual del concepto de derecho

El concepto de DDHH es compuesto: se compone de los conceptos de «derecho»y de «humano». Como hemos visto, éstos presentan serios inconvenientes conceptuales, en tanto que no es difícil constatar que la concepción de «derecho»y de «humano» ha cambiado considerablemente a lo largo de la historia (nomos, ius y law no significaban lo mismo, respectivamente, para un griego del siglo $\mathrm{V}$ a.C., un romano del siglo I d.C. o un inglés del siglo XVII), pero aún si restringimos la mirada a nuestra época, nos encontramos también con una suerte de Babel conceptual, sobre todo si, además de las perspectivas filosóficas, consideramos las concepciones ético-jurídicas, políticas, las manifestaciones populares (reclamos por los DDHH), etc.

En lo que sigue presentaremos a modo preliminar un análisis jurídico-conceptual del concepto de derecho. Tomaremos como apoyo el análisis conceptual presentado por C.S. Nino, no para analizar su teoría - no podemos entrar aquí en este tema- sino para tomar un punto de partida conceptual, mostrar las inevitables limitaciones inherentes a una caracterización jurídica de los DDHH, y pasar luego a presentar una interpretación fenomenológica de los mismos.

En un conocido y canónico manual de derecho, C. S. Nino señaló la gran ambigüedad que envuelve al concepto de «derecho» (Nino, 1973). ${ }^{2}$ Dicha ambigüedad no es mera sinonimia casual -como sería el caso de «banco»-, sino una sinonimia constitutiva puesto que el término «derecho» se utiliza con diferentes significados, pero relacionados entre sí. Así cuando decimos: "El derecho argentino no prevé la pena capital", "Tengo derecho a vestirme como quiera" o "El derecho es una las disciplinas teóricas más antiguas”, nos estamos refiriendo a tres significados diferentes. En el primer caso, hablamos de «derecho objetivo» en tanto ordenamiento o sistema de normas (conjunto de leyes, decretos, costumbres, sentencias, etc.); en el segundo caso, de

2 Es en su obra, Nino (1984) lleva a cabo un detenido análisis de los DDHH y de algunas de las principales posiciones al respecto. Presenta su teoría de los DDHH en términos de derechos morales fundamentales. Lamentablemente, no podemos entrar detenidamente aquí en este tema, por lo que solo nos referiremos a este texto de modo tangencial. 
"derecho subjetivo", refiriéndonos a las facultades, atribuciones, permisos, posibilidades, etc. que tiene un sujeto (individual, jurídico o colectivo); en el tercer caso, la referencia es a la ciencia jurídica que tiene por objeto el estudio del derecho (Nino 1980: 14). Indudablemente, son los derechos en sentido subjetivo los que nos interesan en primer lugar, y el «derecho objetivo» en un sentido derivado, en tanto objetivación y materialización de un derecho subjetivo.

Nino sostiene que el «derecho subjetivo» se suele calificar en tanto libertad, permiso, licencia, atribución, privilegio, facultad, poder, posibilidad, garantía, etc. (Nino 1980: 195) y distingue seis tipos diferentes de derechos subjetivos: 1) como lo «no prohibido», es decir, cuando no hay ninguna norma que establezca una sanción para una acción determinada, por ejemplo «Tengo derecho a caminar libremente por las calles de mi ciudad»; 2) en tanto «autorización», es decir, cuando se refiere a la existencia de normas que permiten o autorizan ciertos comportamientos, por ejemplo: "En mi trabajo tengo derecho a 30 días de vacaciones al año"; 3) en tanto correlato de una obligación activa, como, por ejemplo, al decir "Tengo derecho a exigir a mi deudor que me pague", se trata de un derecho que se da en el marco de una «(co)-relación jurídica», es decir, su correlato es el deber o la obligación de otra persona (en este caso, de pagarme la deuda); 4) en tanto «correlato de una obligación pasiva», un caso similar al anterior, aunque aquí el correlato no es una obligación de hacer, sino de no hacer, como por ejemplo: "Tengo derecho a descansar sin que me molesten”; 5) el «derecho procesal» es el derecho a recurrir a tribunales: "Tengo derecho a iniciar un juicio por calumnias contra mi persona”; 6) el «derecho político» es un caso complejo en tanto presupone un estado que garantiza ciertas facultades a los ciudadanos, como por ejemplo: "El pueblo tiene derecho a elegir a sus gobernantes" o "La libertad de prensa es un derecho de la sociedad" (Nino 1980: 198-207; Nino 1984, 25 y ss.).

Conforme a la clasificación ofrecida por Nino, podríamos decir prima facie que los DDHH serían en primer lugar derechos subjetivos, que serían potencialmente objetivables y pasarían así a formar parte del derecho objetivo, en la medida en que un ordenamiento jurídico legisle sobre los mismos y les otorgue fuerza de ley. Ahora, 
cuando decimos, por ejemplo: "Soy libre para decidir y disponer de mi vida" o "Tengo derecho a vivir y a que se respete mi vida", o bien "Tengo derecho a ser tratado como un igual más allá de mi raza, credo, sexo, etc.", vemos que la clasificación jurídica de Nino es insuficiente para categorizar estos derechos, en tanto éstos son presupuestos por la clasificación. En otras palabras, la clasificación realizada por Nino de los derechos subjetivos se limita a conceptualizar y clasificar derechos subjetivos en el marco del derecho positivo. Todas las facultades enumeradas arriba, si bien son sin dudas subjetivas, se sustentan en la existencia de un derecho positivo objetivo y no son anteriores a éste. De este modo, podemos ver que los derechos subjetivos enumerados no alcanzan para definir los DDHH. Quizás éstos se podrían considerar a la luz de los derechos políticos (6); sin duda, los derechos políticos son garantías en un sentido general -es decir, «del pueblo»- que tienen (o deberían tener) una validación jurídica. Pero su ser «políticos», los vincula ipso facto a una organización y decisiones políticas determinadas, siendo por ende un resultado de las mismas. En tal sentido, recaeríamos en una concepción muy estrecha, i.e. solo política, y marcadamente positivista de los $\mathrm{DDHH}$, en tanto serían decisiones políticas las que darían validez y legitimidad a los mismos.

Debe quedarnos claro que los DDHH, en tanto derechos fundamentales que se dan por el «mero hecho o naturaleza de ser hombre», trascienden la clasificación estrictamente técnico-jurídica de Nino (e incluso la clasificación política de los mismos), llevándonos a cuestiones filosóficas en torno a la (eventual) naturaleza de estos derechos que, en principio, están «más allá» de cualquier derecho positivo. En la misma obra analizada, Nino sostiene que se trata de derechos «morales», pues no son jurídicos sino anteriores a éstos. ${ }^{3}$ Ahora, si

3 En efecto, la propuesta de Nino en el texto que aquí no analizamos es entender a los $\mathrm{DDHH}$ en términos de derechos morales, es decir, derechos que remiten a principios morales básicos que por su misma universalidad deberían ser aceptados por todos (Nino, 1984: 20, 24, 41, 46, 48 nota). La postura de Nino de entender los DDHH en tanto derechos morales parece oscilar entre un positivismo (fruto de su firme ataque al iusnaturalismo) y un no-positivismo, es decir, una posición que sostiene una restricción moral al derecho en cuestiones básicas de principios universales. Lamentablemente, no podemos analizar aquí su posición. En cualquier caso, queda claro que dichos «dere- 
entendemos por moral el uso o ethos propio de una determinada comunidad, dicha caracterización se relativizaría contextual e históricamente, impidiéndonos eo ipso hablar de DDHH. Por ende, si por DDHH nos referimos a aquellos derechos ínsitos a la misma naturaleza de lo humano, vemos que éstos no son en su misma naturaleza ni derechos jurídicos ni derechos meramente morales. ${ }^{4}$ La pregunta es, entonces, en el marco de este complejo enjambre de derechos subjetivos, objetivos, políticos, naturales, positivos, etc., ¿de qué tipo de derecho estamos hablando cuando nos referimos a los DDHH?

En función de lo que acabamos de exponer, podemos al menos concluir que los DDHH: i) son «subjetivos», en tanto aquél que lo ostenta es un sujeto; ii) en tanto tales, son «individuales» y sólo en un sentido derivado, secundario, «colectivos»; iii) son «básicos» $\mathrm{y}$ «fundamentales», en la medida en que subyacen a cualquier ordenamiento jurídico, y, por ende, son anteriores o independientes a cualquier sistema jurídico o moral. Probablemente, la mayoría de las posiciones (aún los iuspositivistas más radicales) podrían coincidir en los puntos i) y ii). Es quizás el punto iii) el que presenta más inconvenientes, en tanto excede el orden jurídico positivo y demanda una justificación de otra índole.

Pensar los DDHH desde una perspectiva filosófico-fenomenológica ${ }^{5}$

La pregunta es ahora: la fenomenología ¿tiene algo que decir o aportar en este contexto? Nuestra propuesta será presentar un análisis

chos morales» están más allá del derecho positivo con lo que, al menos en este punto, Nino coincidiría con la posición que defendemos aquí.

4 No queremos negar aquí el hecho de que Nino no defiende una moral del ethos de tipo artistotélico, sino una moral universalista de tipo kantiano, como él mismo reconoce (Nino, 1984: cap. 4, § 3). En cualquier caso, es una moral que postula contenidos universales, tales como los principios de autonomía, de inviolabilidad y de dignidad de la persona, a partir de los cuales, a su vez, se derivan otros contenidos (los DDHH). No podemos detenernos aquí en los límites de la posición defendida por Nino.

5 Si bien se tomarán numerosos elementos conceptuales de la fenomenología de Husserl, es fundamental aclarar, como dijimos en la Introducción, que la presente exposición no pretende ser un comentario o un análisis de su obra; de hecho, varios de sus conceptos serán utilizados en un sentido distinto al dado por Husserl. 
fenomenológico descriptivo del modo de «ser básico y fundamental» de los DDHH, tal y como planteamos arriba. Nuestro recorrido será así el siguiente: primero, explicitar fenomenológicamente el sentido propio de ser «humano» a partir de la diferenciación entre la dimensión empática y la dimensión moral; segundo, mostrar que la génesis de mi propia subjetividad en su relación con los otros (mi primera intersubjetividad) nos hace patentes mis derechos en el sentido más elemental, así como el sentido de los derechos del otro en tanto mis límites; tercero, presentaremos una interpretación de las diferentes instituciones históricas de los DDHH en términos de instituciones de sentido (Urstiftungen), que objetivan, en un sentido transgenético e intergeneracional, las formas básicas de constitución de la subjetividad; veremos cómo dichas objetivaciones son acontecimiento histórico-fácticos y, en tanto tales, contingentes, pero que constituyen objetividades con validez eidética-universal.

Reconocimiento empático y reconocimiento moral del «otro humano»

Sin duda, el concepto de «humano» es de una extrema complejidad, aún mayor que el de derecho, en tanto él mismo, en su uso cotidiano y pre-temático, presupone una superposición de concepciones filosóficas, científicas, religiosas, morales y aún jurídicas. Definir qué es lo humano equivale a definir qué es el hombre, cuestión antropológica que ha sido abordada históricamente desde las más diversas perspectivas. Podemos decir que «lo humano» se refiere a todo ser animal que conforma la especie, definida biológicamente, como homo sapiens, perteneciente a la familia de los homínidos. Se trata de animales superiores (en su desarrollo fisiológico) que se definen por poseer un determinado cuerpo con ciertas características morfológicas, tener inteligencia (actual o potencialmente), y que se comunican a través de un lenguaje. Pero éste es solo un modo posible de definir lo humano que acarrea con la pesada carga semánticoconceptual de un discurso científico específico, que bien podría ser otro, como por ejemplo el de una ciencia social. 
Por ello mismo, nuestra propuesta fenomenológica consiste en efectuar una suerte de epoché que deje entre paréntesis dichas concepciones científicas (y sus conceptos concomitantes) y nos conduzcan al modo en que se nos muestra lo humano del otro en nuestra experiencia concreta. O quizás aún de un modo más radical, ¿cómo se nos muestra el otro humano? ¿Cómo aparece (un) otro en nuestro campo de experiencia? Mostrar fenomenológicamente dicho «aparece» presupone el arduo ejercicio de dejar de lado toda precomprensión o pre-suposición que se superponga -en muchos casos sin darnos cuenta- a nuestro experimentar fáctico, concreto. ¿Qué es lo que podemos «ver»? En primer lugar, que hay una base dada por la intuición sensible: la percepción externa del cuerpo de (un) otro, distinto pero similar a mí, en tanto cuerpo viviente $\left(\right.$ Leib). ${ }^{6}$ En segundo lugar, sobre la base de dicho acto perceptivo directo se ejecuta al mismo tiempo ${ }^{7}$ un acto empático. Para Husserl, el concepto de empatía remite a la experiencia de un otro en tanto otro humano: se trata así de una «apercepción analogizante», a partir de la cual captamos a otro en tanto un "análogo de mi interioridad (Analogon meiner Innerlichkeit)" (Husserl, Hua XIV: 5), al cual de un modo espontáneo y básico -i.e. no inferencial- le atribuyo sensaciones, libertad de movimiento, conciencia de sí (en sentido elemental), un punto de vista, desde su lugar en tanto punto cero, etc.

Dejando de lado la letra de Husserl en sentido estricto, ${ }^{8}$ podemos decir que la empatía es el modo más básico de «ver» al otro en tanto otro humano. En tal sentido, podemos hablar de «reconocimiento empático» de un otro similar (en su diferencia) a mí; en otras palabras: sabemos qué o quién es otro, es decir, otro ser humano.

6 Husserl distingue la dación originaria de un objeto en tanto «presentación» (Gegenwärtigung), de la dación no originaria, es decir, que da un objeto, pero no en persona o en sentido originario y que denomina «presentificación» (Vergegenwärtigung). Mientras que la percepción es una presentación, la empatía es una presentificación, pues no tenemos (ni podemos tener) una dación directa del otro.

7 Es decir, no se trata de una inferencia o acto secundario seguido de un acto primario, sino de una diferencia lógica, i.e., una relación de fundación.

8 Si bien asumimos explícitamente conceptos husserlianos y muchos de los lineamientos de sus obras, la descripción aquí realizada es propia. 
Dicho acto empático debe diferenciarse claramente del «reconocimiento moral» del otro, en tanto éste, en primer lugar, presupone a aquél, y, en segundo lugar, presupone además una base moral de aceptación del otro en tanto sujeto ético, concepto que a su vez puede implicar el merecer respeto, la igualdad de trato, etc. Nuestra propuesta fenomenológica consiste en sostener que aun cuando no se da siempre un reconocimiento moral del otro, siempre se da un reconocimiento empático del otro, i.e. siempre sabemos cuándo hay enfrente otro (humano, es decir, como yo), ya que de lo contrario ni siquiera podríamos darnos cuenta de que estamos en presencia de otro (hombre).

Por supuesto, se podría pensar en objeciones basadas en ejemplos históricos e incluso actuales que prima facie refutarían dicha evidencia fenomenológica, como por ejemplo en los conocidos casos de discriminación racial en donde «el otro» (el bárbaro, el negro, el indio, el judío, etc.) no es reconocido en tanto hombre. De todos modos, si miramos detenidamente con la lupa fenomenológica, vemos que en cada uno de estos casos, lo que constatamos es una fractura entre el reconocimiento empático y el reconocimiento moral. Es decir, en los casos mencionados arriba, vemos que no reconocemos «moralmente» al otro como «uno de nosotros». Por su parte, el reconocimiento empático es un acto mucho más elemental que no presupone dicha esfera axiológica de valoración ética, vemos así que hay un reconocimiento del otro en tanto «otro (hombre)», aún ante el desconocimiento radical de éste en tanto un «igual moral». Incluso si pensamos los casos de negación más extremos del otro, como por ejemplo, cuando los colonizadores europeos se encontraron con tribus aborígenes americanas, por más etnocéntrico y denigrante que hubiese sido el modo de «ver» a este «otro», en ningún caso podemos decir que no se lo vio como «otro humano».

¿Qué significa esto? Que si nos atenemos a un nivel estrictamente fenomenológico-descriptivo, ni las diferencias de color de piel, ni las diferencias lingüísticas (aun cuando estas sean casi inconmensurables), ni las diferencias de comportamiento o de vestimenta (por más primitivas y precarias que éstas sean) pueden (o pudieron, en su momento histórico) llevar a creer que se trata (o se trataba) de 
un animal. Ninguno de los navegantes de las tres carabelas en su sano juicio pudo haber pensado que los aborígenes taínos (habitantes precolombinos de las Bahamas y Antillas) eran animales en el mismo sentido que pudiese haberlo sido un papagayo o incluso un primate. En ningún caso, en un sentido básico de nuestra experiencia empática de los otros, confundimos a un «otro» con un chimpancé o con un perro; éstas son formas de experiencia empática básicas propias de nuestro mundo de la vida. Por supuesto, ya en un sentido moral sí podemos (y de hecho se puede constatar esto a lo largo de la historia) «ver al otro» no en tanto otro, sino en tanto animal, primitivo, bárbaro, etc. Así, no debemos confundir la «dimensión empática» con la «dimensión moral». Ningún nazi trató a un judío como lo hubiese hecho con un caballo o un perro. El mero hecho de haber interactuado, hablado con ellos, de haberles prohibido primero ciertos derechos, luego haberlos proscripto y encerrado, para finalmente deportarlos y exterminarlos, habla de una dimensión de empatía diferente a la que podemos llegar a tener con un animal no humano; a nadie se le ocurriría prohibirle a un perro el derecho de participación política o exterminarlo por motivos raciales. ${ }^{9}$ En cualquier caso, se puede exterminar a un animal (o una especie animal), pero el sentido y la significación es completamente distinta. Más allá del cariño y afecto que podamos tener con una mascota, aun cuando de hecho podamos tener por ésta mucho más aprecio y apego que con la gran mayoría de los 'humanos' (algo que de hecho suele suceder), sabemos en cualquier caso que no es un humano. La diferencia entre el «reconocimiento» y el «aprecio o apego» patentiza la diferencia fenomenológica fundamental entre la dimensión empática y la dimensión moral. En tal sentido, reconocer empáticamente al otro en tanto «otro humano», no significa tenerle ni aprecio ni cariño, ni siquiera que lo reconozca en tanto sujeto moral; incluso puedo odiarlo y querer matarlo (algo que sucede a menudo en nuestros

9 Richard Rorty plantea dicho problema como fundamental, aludiendo al caso particular de los serbios que no reconocían a los musulmanes en tanto que «humanos» (1993). En cualquier caso, creemos que dicho ejemplo hace patente la confusión de Rorty de las dos dimensiones planteadas aquí: el no-reconocimiento es a nivel moral, no a nivel empático. 
días), pero en cualquier caso, simplemente sé que el otro es un «otro humano». ${ }^{10}$

En síntesis, podemos decir que «lo humano» es todo aquello que remite a un «otro humano» en la medida en que podemos reconocerlo, captarlo intuitiva y empáticamente en tanto tal, más allá de cualquier tipo de valoración moral.

La constitución genética de la conciencia de mis derechos y límites básicos desde una perspectiva fenomenológica: mi libertad y mi vida y la libertad y la vida del otro

Nuestra meta ahora es mostrar, descriptivamente, el modo en que la constitución genética de mi subjetividad es asimismo una constitución de mis derechos básicos; en este marco, no debemos olvidarnos que no estamos refiriéndonos a derechos en sentido jurídicos, sino al sentido más elemental de derechos en sentido subjetivo, que se constituyen genéticamente desde mi más temprana edad en relación con los otros. De este modo, cuando en adelante hablemos de «derechos» debemos entender esto en un sentido genético elemental, pre-jurídico, en tanto aquello que reclamo y exijo (con pretensión de «derecho») desde el desarrollo mismo de mi pre-conciencia en su relación intersubjetiva hasta las formas más complejas de conciencia y de autoconciencia de mi subjetividad. Ahora, ¿cuáles son estos derechos básicos?

Para Husserl, la subjetividad - en un sentido más estrecho el yose constituye en sentido genético a partir de un pre-yo (Vor-Ich), aún no plenamente consciente de su ser yo. Dicha constitución de mi yo se da en directa correlación intersubjetiva con otros yoes ya constituidos (padres, tíos, maestros, etc.), de otros pre-yoes en vías de constitución (hermanos, compañeros de escuela, etc.) e incluso de

10 Por supuesto, hay casos complejos que podrían presentarse en donde el reconocimiento empático se torna difuso como, por ejemplo, el de los humanos pre-natales (en donde debería entrar en consideración la dimensión de lo potencial), que se aplicaría asimismo a un bebé recién nacido o una persona en estado vegetativo, etc. No podemos analizar este tema aquí. 
animales no humanos (los perros, por ejemplo, nos ayudan a constituir el mundo). El niño en tanto pre-yo, se encuentra en un mundo que aún no es tal, sino que es un pre-mundo, que empieza a conocer, a significar y luego a nombrar. Dicho conocimiento del mundo está ligado a dos cuestiones: el (re)conocimiento de mi propio cuerpo viviente (Leib) y la relación con otros cuerpos vivientes, que son todos los otros que entran en mi horizonte intersubjetivo (por lo general, los primeros suelen ser los padres y, eventualmente, los hermanos). Mi cuerpo viviente y mi mundo están íntimamente relacionados. Mi cuerpo es antes que nada corporalidad viviente (Leiblichkeit), i.e. un conjunto de cinestesias, de movimientos a partir de los cuales puedo comenzar a constituir el mundo que me rodea (Umwelt). Mi desarrollo más temprano consiste así en los movimientos de mi cuerpo en el marco de una esfera espacial potencialmente abierta; la constitución de mi «subjetividad cinestésica» coincide así con mi «primera libertad», que es precisamente la de adquirir conciencia de mi libertad de movimientos, de extender la mano, tomar cosas, sentir su sabor cuando la coloco en mi boca, sentir un ruido y alejarme o acercarme a éste, ver un color llamativo y querer tocarlo; es a partir de dichas sensaciones que reciben mis órganos sensoriales y de la posibilidad de movimiento en un sentido básico, que llego a la conciencia elemental de un «yo puedo» (ich kann), que en tanto poder potencialmente abierto constituye un yo quiero, que mueve mi cuerpo, aprende a utilizarlo, y adquiere así conciencia de su vida y de su libertad. La libertad en sentido primigenio se trata de una «capacidad» (Vermögen), un «yo puedo» (ich kann) (Husserl, MatVIII: 90).

En otras palabras, la constitución más básica de mi libertad es a partir del movimiento de mi cuerpo, y de la conciencia que adquiero gradualmente de ser yo ese cuerpo que se constituye desde los comienzos mismos de la proto-génesis de mi yo. En este contexto, aprendo (a partir de accidentes, golpes, lastimaduras, etc.) que mi cuerpo y, en el límite, mi vida, implican un cuidado de mí mismo que pasa a ser un componente central en la formación de mi subjetividad. El cuidado de mi corporalidad (Leiblichkeit) se impone genéticamente como un modo de ser básico del pre-yo en formación, que aprende a ser un yo en la medida en que cuida su cuerpo, i.e. lo aleja 
y lo protege de aquello que lo daña. En tal sentido, el yo consciente o pre-consciente de su cuerpo viviente le exige al otro un respeto por su cuerpo, que se suma a la exigencia de la libertad de movimientos.

Pero en este marco, se puede evidenciar asimismo que la relación intersubjetiva es un componente constituyente esencial en el desarrollo de mi subjetividad. Los otros están ahí, e interactúan aceptando o bien poniendo límites a mi libertad primigenia y son, también, aquellos que pueden amarme pero, también, quienes pueden lastimar mi cuerpo y, en el límite, mi vida. Pero, cualquiera que sea el caso, siempre hay otro allí, delante de mí, en el proceso de constitución de mi subjetividad en relación directa o potencialmente directa con mi yo. Es imposible pensar en una subjetividad que se constituye genéticamente sin otros que estén ahí, ayudándome a crecer y a formarme, a facilitarme el aprendizaje de mi movimiento corporal (los padres que enseñan a un hijo a caminar), a aprender un lenguaje, y a proteger y cuidar mi cuerpo. Por supuesto, es innegable que hay casos en los cuales dicho acompañar de los otros se da en un contexto de hostilidad; en efecto, la relación primigenia con los otros puede ser de amor, pero también de indiferencia e incluso de odio. Un ejemplo de estos casos es el maltrato infantil; sin dudas, en estos casos el desarrollo subjetivo adquiere otro cariz (que aquí no podemos abordar). Pero estos casos extremos no hacen otra cosa que confirmar la evidencia fenomenológica de que el desarrollo de mi subjetividad está estructuralmente ligado a mi relación intersubjetiva con los otros. Es incluso en dichos contextos intersubjetivos adversos en donde se hace más patente la constitución de la conciencia de la necesidad de salvaguardar aquello que me es más preciado, mi cuerpo, mi vida, y mi libertad.

Entonces, el otro siempre está allí, sea para ayudarme, para castigarme o dañarme, o simplemente para ser indiferente a mi presencia. Cada uno de estos posicionamientos del otro condiciona y co-constituye mi propia subjetividad; y cada uno de los modos de relación del otro (amor, hostilidad, indiferencia, aprecio, etc.) generan una reacción de mi parte (cariño, miedo, odio, indiferencia, necesidad de protección, etc.). Es precisamente en esta primigenia interacción intersubjetiva donde se constituye en sentido básico mi 
capacidad de defender(me) (en el límite, de defender mi vida) y de defender mi libertad, i.e. el libre desarrollo de mis posibilidades y potencialidades subjetivas.

Ahora, si nos detenemos en esta descripción, podemos constatar que la relación con los otros abre no sólo una dimensión «centrípeta» que lleva al cuidado de mí mismo, sino que a su vez su vez abre una dimensión «centrífuga», i.e. mi experiencia es también un salir al encuentro del otro, que me implica además un modo de tratar al otro. Es decir, el otro no es sólo mi primer límite en sentido negativo, sino también en sentido positivo, en tanto el otro también exige, en el marco de sus posibilidades y potencialidades, un respeto por su libertad y por su propio cuerpo y, en el límite, por su vida.

Los primeros otros (mis padres, hermanos, amigos, primeros maestros), no son sólo nuestra primera red de contención, que nos enseñan a cuidar lo más preciado que tenemos (mi vida y mi libertad), sino que también se me imponen como límites, en primer lugar a mi libertad. Los padres que retan al niño, los hermanos y amigos que dicen no a mi libertad «omnipotente», el maestro que le imparte una orden al niño. Lo importante a destacar en este contexto es la idea de «límite» que me impone el otro. La conciencia de mi límite se constituye de un modo concomitante a la conciencia del límite que impone el otro, ahí, delante de mi subjetividad. Es así que la interacción intersubjetiva se constituye a su vez en el aparecer de un otro que defiende su libertad y su cuerpo (su vida), imponiéndome el respeto a su libertad y a su cuerpo (vida); dicha conciencia del respeto del otro se adquiere gradualmente a partir de la interrelación con los otros.

Así, en un sentido básico, elemental, vemos que en la constitución de mi subjetividad el otro aparece como un límite: en «sentido negativo», en tanto mero condicionamiento de mi libertad, pero también en «sentido positivo», en tanto exigencia, demanda de respeto por su vida y su libertad. Es a lo largo de la formación de mi subjetividad que aprendo a exigir y ejercer mis «derechos básicos» en correlación con una comunidad de «yoes», que a su vez me exigen un respeto de sus «derechos básicos». Fenomenológicamente, podemos decir que este reconocimiento de los derechos del otro, es 
la primera conciencia de una «ley» en sentido básico, que me exige respetar al otro en tanto otro. De este modo, mis derechos (en sentido pre-jurídico) a mi libertad y a mi vida (en general, al cuidado de sí), se constituyen intersubjetivamente a partir de la correlación que estos implican de respetar los mismos derechos del otro.

¿Podemos decir que dicha «descripción fenomenológica» abre una «dimensión prescriptiva o normativa»? Esta pregunta oculta una trampa, que es la presuposición de una dicotomía indeclinable entre el orden del «ser»y el orden del «deber ser»; dicho presupuesto, debería, en virtud de nuestra exigencia metodológica originaria, quedar entre paréntesis, para circunscribirnos a «ver» solo aquello que aparece en nuestra experiencia. La descripción presentada aquí no se basó ni en la postulación de un orden ontológico del ser, ni en la consecuente derivación de un orden deontológico del deber ser; en cualquier caso, dichas afirmaciones «metafísicas» presuponen lo dado en mi experiencia, que no es del orden del ser, ni del orden del deber ser, sino que es anterior a éstos. En conformidad con el método fenomenológico propuesto, cualquier afirmación con tenor «metafísico» debe sostenerse sobre la base de la dimensión descriptiva de mi experiencia. En efecto, es solo a partir de ésta que encuentro ciertos rasgos «eidéticos», es decir, estructuras universales (de mi subjetividad, del otro, de la intersubjetividad en general, de la comunidad, de las demás comunidades, de las diversas generaciones de comunidades en una historia común, etc.) que se muestran a modo de leyes no en sentido «normativo», sino en sentido «descriptivo», ${ }^{11}$ como caracteres eidéticos que veo a partir de mi propia facticidad experiencial. Nos encontramos aquí en un marco estrictamente descriptivo, que nos muestra que nuestra propia subjetividad demanda derechos propios e impone el respeto a derechos ajenos, a partir de la conciencia de mi libertad y de mi vida, y el respeto por el otro, constituyendo de este modo la base de la conciencia de derechos

11 Aquí tomamos la idea de Frege del doble sentido del concepto de «ley» (Gesetz): por un lado, en sentido descriptivo "que dice lo que es", por otro lado, en sentido prescriptivo "que prescribe lo que debe ser"; el primer sentido es, por ejemplo, el de una ley de la naturaleza o una ley lógica, y el segundo sentido es, v.gr., el de una ley moral, jurídica, etc. (Frege 1893: Xv). 
básicos fundamentales (en cualquier caso, pre-jurídicos e incluso pre-morales). Dicha descripción nos permite (simplemente) mostrar de qué modo somos conscientes de lo que es un derecho con anterioridad genética a todo ordenamiento jurídico. Que en base a dicha exigencia que encontramos a partir de nuestra misma facticidad, se imponga a su vez un orden normativo positivo (sea moral o jurídico), implica en cualquier caso una objetivación, pero que sobreviene sobre la instancia fundante de aquellas leyes que aparecen en la descripción mi experiencia.

La Urstiftung de los DDHH en tanto fundación de sentido en la historia de la humanidad

Ahora, ¿cómo llegamos entonces a los derechos humanos y cómo podemos relacionarlo con lo anterior? Como dijimos, la descripción realizada nos permite ver que nuestra experiencia nos presenta ciertos rasgos eidéticos constitutivos de mi subjetividad y de las demás subjetividades en sus diferentes relaciones intersubjetivas y trans-subjetivas: estos «derechos humanos básicos» son como vimos el derecho a la vida (y su cuidado) y a la libertad (en el sentido más elemental del término). Estos derechos elementales pueden objetivarse, al instituirse en la historia, a partir de un reconocimiento de los mismos. En efecto, dicho reconocimiento (no en tanto meros derechos positivos, sino en tanto derechos de todo hombre), se dio en la historia en un nivel trans-subjetivo o intergeneracional (es decir, que se extiende a la humanidad excediendo el marco de interacción de mi intersubjetividad actual o potencial directa), a partir de ciertos acontecimientos en los que se institucionalizaron los derechos humanos a través de declaraciones históricas, en particular en la Declaración de Independencia de los EE.UU., en la Declaración de los derechos del hombre en la Revolución Francesa, en la Declaración Universal de los DDHH, etc. La declaración de los derechos del hombre en tanto tal no hacen otra cosa que reflejar, objetivar y universalizar aquello inherente a la experiencia de cada subjetividad en su relación intersubjetiva. 
La definición de «libertad» dada en la Declaración Francesa de los Derechos del Hombre de 1789 sostiene que: "La libertad consiste en el poder de hacer todo aquello que no dañe a otros; así, el ejercicio del derecho natural de todo ser humano tiene como límites solo aquellos que aseguran a otros miembros de la sociedad el uso de estos mismos derechos" (Art. 4). Se puede observar que la caracterización es profundamente «descriptiva» en tanto muestra en qué consiste la libertad y cuál es el límite a la misma. Más que un mero acuerdo positivo de partes (en sentido jurídico), se muestra como un reconocimiento intersubjetivo y trans-subjetivo de aquello que, con una mirada atenta, cada hombre puede encontrar en su misma experiencia y que, por ende, no es un constructo metafísico artificial o el resultado de un mero pacto de partes. En otras palabras, se trata de reconocer aquello que ya todos sabemos (por nuestra propia constitución) porque es el modo a partir del cual llegamos a ser lo que somos.

En función de lo dicho, podemos ver que las diversas declaraciones históricas de los DDHH, que mencionamos arriba, pueden entenderse a partir del concepto husserliano de «proto-fundación» (Urstiftung), ${ }^{12}$ i.e. de una institución de sentido que acontece en el marco de la facticidad histórica, pero que constituye una fuente de validez y de legitimidad que desborda, en reconocimiento universal, el marco mismo de la facticidad que es su fuente. Ahora, la conjugación entre facticidad y validez universal nos coloca ante un modo diferente de ver los DDHH que no encuadra en el marco del clásico debate entre iuspositivismo e iusnaturalismo. En un sentido fenomenológico, los DDHH no son ni derechos naturales ni derechos positivos. No son naturales porque, primero, no corresponden a una naturaleza ontológica o metafísica supra-empírica que esté más allá de la facticidad; segundo, no son algo que se pueda descubrir o postular de un modo puramente racional, a priori; tercero, porque su historia es fáctica, y en tanto tal contingente, es decir: su reconocimiento e institución, bien podría no haberse dado nunca. ${ }^{13}$ No son positivos,

12 La Urstiftung es una donación de sentido primaria (erstmalig) que da sentido teleológico a un horizonte por venir (Husserl, Hua l, §50).

13 Como sostiene Derrida: "tienen una historia - una que es reciente, compleja, incon- 
pues no son el resultado de una mera convención o acuerdo que solo se impone en virtud de autoridad instituyente (aun cuando ésta pueda alegar una cierta base moral); por el contrario, son derechos cum fundamento in re, es decir, son algo que no solo puedo encontrar en mi experiencia, sino que, a partir de remisiones intencionales intersubjetivas y trans-subjetivas, aparecen en toda subjetividad que indague en su propia experiencia. Sobre esta base las respectivas Urstiftungen históricas instituyen una validez y legitimidad de alcance universal.

La Urstiftung es historia, i.e., no es nada antes de la institución misma, solo pura potencialidad en mayor o menor medida realizable. Ésta «funda» $\mathrm{O}$ «instituye» algo nuevo en la historia (en nuestro caso, los DDHH), que une y obliga (verbindet) a las generaciones por venir en la medida en que estos sentidos se proyectan (fortleben) en formas de sedimentaciones y de nuevas confirmaciones (Nachstiftungen) que ratifican ese sentido originario y lo hacen sobrevivir para las futuras generaciones (Husserl, Hua VI: 72). Es precisamente el carácter histórico, temporal, instituido el que hace patente el lado fáctico de los $\mathrm{DDHH}$; como ya dijimos, la proto-fundación de los DDHH pudo no haberse dado nunca, y esto habla de su contingencia estructural en tanto institución de la humanidad. No hay aquí marco alguno para una lectura dialéctica (hegeliana o marxista) de la historia, que, desde una perspectiva fenomenológica, no sería otra cosa que una construcción metafísica impuesta al acontecer mismo de la experiencia. La contingencia de la proto-fundación rechaza toda idea de necesidad intrínseca a la historia; por supuesto, hay hechos históricos e intelectuales que coadyuvaron a la declaración de los DDHH, pero son solo eso, i.e., hechos históricos concretos, únicos y absolutamente contingentes en su fragilidad histórica. Pudo no haber nacido Locke, o incluso, pudo haber fracasado la Revolución Francesa o la Independencia de los EE.UU., con lo cual se hace patente su fragilidad, así como el inmenso valor de que algo así haya ocurrido. ¿Debemos entonces defender y sostener dicha validez instituida en estos acontecimientos históricos?

clusa" (Derrida, 2003: 132; Levinas, 1985: 164). 
El «deber» que aquí está en juego no es algo que remita a una dimensión deontológica o una instancia prescriptiva. El «deber» del que hablamos aquí nos remite, en su sentido más básico, a la institución objetivada de aquello que es lo más humano, que aparece en mi más íntima esfera subjetiva, en su necesaria correlación intersubjetiva con el otro; como vimos, esto es el derecho a mi vida y a mi libertad y, en tanto intersubjetiva, el derecho del otro, en el límite, podríamos decir de todos los otros, o bien, de modo abstracto, de la humanidad. Así, el «deber» planteado aquí, no tiene otra intención que hacernos recordar que más allá de cualquier discurso teórico, en la raíz misma de nuestra facticidad concreta, somos humanos y en tanto tales tenemos derechos fundamentales (anteriores al derecho mismo, subjetivo u objetivo, como se ha planteado en el capítulo dedicado a Nino), que se dan al mismo tiempo con la patencia de un límite que impone el otro, cuyo rostro, como diría Levinas, se me muestra antes de toda sospecha, de toda duda, de todo discurso, como límite que exige su derecho a vivir y ser libre. La facticidad misma de nuestra subjetividad en su relación experiencial con el otro nos coloca siempre «más acá» de toda metafísica, de toda ontología o de una axiología, pero también «más acá» de toda duda, de todo escepticismo y de todo nihilismo, que, en última instancia, siempre parte de evidencias primarias que ya tenemos en nuestra vida concreta; nuestra libertad y nuestra vida (los bienes más preciados que tenemos) y nuestro respeto del otro (hombre) no necesitan ser legitimados exógenamente a partir de discursos teóricos prescriptivos y abstractos, sino que son evidencias básicas del mundo de la vida, que, como se dijo, se muestran temáticamente a partir de una atenta descripción fenomenológica.

Las Urstiftungen de los DDHH que heredamos trans-generacionalmente desde el siglo XVIII en adelante, son instituciones que, como se dijo, nunca están (ni estarán) exentas del peligro sea ya de no ser respetadas, ignoradas, o directamente negadas; es así esta contingencia fáctica la que nos coloca ante una infinita responsabilidad, que no sólo es pre-jurídica, sino que también es pre-moral, en tanto consiste meramente en un «responder» a mi propia historia, a la historia del otro y, en el límite, a la historia de la humanidad. 
En tal sentido, «responsabilidad» no quiere decir aquí otra cosa que re-conocer, y, en tanto tal, «responder» a las «proto-fundaciones» originarias, a partir de «pos-fundaciones» (Nachstiftungen), o bien de «nuevas-fundaciones» (Neustiftungen) o refundaciones. En síntesis, podemos decir que el reconocimiento fenomenológico de los DDHH no es otra cosa que un mirar a los derechos más fundamentales a partir de su misma fuente de legitimidad, que nos hace patente que los DDHH humanos no son en primer lugar un mandato de orden prescriptivo, sino la conciencia de derecho de uno mismo, del otro, y, en el límite, de la humanidad.

\section{Referencias bibliográficas}

Alexy, R. (1992). Begriff und Geltung des Rechts. Friburgo: Alber.

Clapham, A. (2007). Human Rights. A Very Short Introduction. Nueva York: Oxford University Press.

Frege, G. (1893). Grundgesetze der Arithmetik, I. Jena: Pohle.

Finnis, J. (2011). Natural Law and Natural Right, 2a ed. Nueva York: Oxford University Press.

Derrida, J. (2003). Philosophy in a Time of Terror. Dialogues with J. Habermas and J. Derrida. G. Borradori, ed. Chicago/Londres: The University of Chicago Press.

Hayden, P. (2001). The Philosophy of Human Rights. St. Paul: Paragon House.

Herbert, G. (2003). A Philosophical History of Rights. New Brunswick: Transaction Publishers.

Husserl, E. 1963. (Hua I). Cartesianische Meditationen und PariserVorträge. En Husserliana I. Den Haag: Nijhoff.

1976. (HuaVI). Die Krisis der europäischen Wissenschaften und die transzendentale Phänomenologie. En HusserlianaVI. Den Haag: Nijhoff.

. 1973. (Hua XIV). Zur Phänomenologie der Intersubjektivität (1921-1928). En Husserliana XIV, Den Haag: Nijhoff.

Husserl, E. 2006. (MatVIII). Späte Texte über Zeitkonstitution (1929-1934). En Husserliana-Materialien VIII, Dordrecht: Springer.

Levinas, E. (1987). “Les droits de l'homme et les droits d'autrui”. En E. Levinas, Hors sujet, Paris: Fata Morgana. 
Muadi Darraj, S. (2010). The Universal Declaration of Human Rights. Nueva York: Chelsea House Publishers.

Nino, C.S. (2003). Introducción al análisis del derecho. Buenos Aires: Editorial Astrea.

Nino, C.S. (2007). Ética y derechos humanos. Un ensayo de fundamentación. Buenos Aires: Ed. Astrea.

Ponton, L. (1990). Philosophie et droits de l'homme. París : Vrin.

Rorty, R. (1993), "Human Rights, Rationality and Sentimentality". En Shute, S. / Hurley, S. (eds.), On Human Rights. The Oxford Amnesty Lectures 1993, New York: Basic Books. 